\title{
Training for approval under Section 12(2) of the Mental Health Act 1983
}

\author{
Nicholas Brown \& Martin Humphreys
}

Abstract The history and meaning of doctors' approval by the Secretary of State under Section 12(2) of the Mental
Health Act 1983 is discussed. The definition for approval is examined with relevant rulings on interpretation.
Training requisites of such doctors are examined, outlining a framework of educational aims and objectives,
with suggestions for delivery. The aims must include direct factual content and also the skills, values and
attitudes required for humane and consistent practice. The particular needs of some specific groups and
individuals are highlighted. The continual learning for updating skills and knowledge, including event-based
learning, audit and reflection, is placed in the context of clinical governance wherein doctors must ensure that
they continue to be 'fit for purpose'. The case is made for 'nationalisation' of the syllabus and standards.

Section 12(2) of the Mental Health Act 1983 states that one of the medical practitioners making recommendations in respect of applications for the involuntary admission of patients to hospital under Part II of the Act should be individually approved by the Secretary of State as having 'special experience in the diagnosis or treatment of mental disorder'. This also applies to certain recommendations to the courts in relation to those involved in criminal proceedings and to the Secretary of State in the case of those serving prison sentences under Part III. There is parallel provision in the legislation for Scotland and Northern Ireland. There are about 6000 approved doctors in England alone.

Approval effectively conveys certain responsibilities and rights to doctors in the area of compulsory detention and the removal of an individual's liberty. Despite this, the Secretary of State 'does not wish to lay down any hard and fast definition of what constitutes such special experience' (Department of Health, 1990). It was not until 1996 that further guidance appeared (NHS Executive, 1996) which outlined requirements for initial and continuing training.

When deciding whether a doctor should be approved under Section 12(2), the Secretary of State or his/her delegate is entitled to have regard to the fitness of the particular individual for the task in hand. In the case of $R$. v. Trent Regional Health Authority, ex parte Somaratne (1993), it was successfully argued that the 'special experience' referred to does no more than provide a minimum threshold requirement before approval can be granted. It is therefore not the only matter which can be taken into account by the Secretary of State. However, this judgement was reversed by a majority in the Court of Appeal, where it was held that 'special experience' is the sole criterion for approving a doctor and that it requires examination of the doctor's current knowledge and skills in the diagnosis and treatment of mental disorder. Thus, the health authority has to consider the doctor's qualifications and experience and not his or her overall suitability for appointment. Following this decision, the doctor concerned made application for judicial review and judgement was made by the Honorable Mr Justice Latham. In dismissing the application, his Lordship held that the health authority was entitled to set an appropriate standard of experience in line with HSG(96)3 (NHS Executive, 1996).

It is important to note that the Mental Health Act refers only to the process of admission to hospital and the making of recommendations for admission in the context of the approval of medical practitioners. This takes no account of the fact that, in caring for detained or voluntary patients in both the hospital and the community, there should be a constant and regular, if not formal, reappraisal of the legal status of each individual involved. The mental health assessment process and completion of the prescribed forms is only part of the legitimate function of the approved doctor. Surely, the work of Mental Health Tribunals reviewing continued

\footnotetext{
Nicholas Brown is a consultant psychiatrist working in general adult psychiatry and based at Lyndon Resource Centre (Hobs Meadow, Solihull, West Midlands B92 8PW, UK). He has particular interests in both training and mental health legislation. He currently chairs the West Midlands panels responsible for training schedules in mental health legislation for a variety of staff groups as well as the specific group for approval and training of medical staff. Martin Humphreys is a senior lecturer in forensic psychiatry at the University of Birmingham, UK, and an honorary consultant psychiatrist at the Reaside Clinic, Birmingham. His research interests include the application of mental health legislation in England and Scotland.
} 
detention or making decisions about the start of enforced treatment ought also to include some formal recognition that a suitably experienced practitioner should be involved?

It is not clear why the Act refers to 'special experience in the diagnosis or [our italics] treatment of mental disorder'. At first sight, it seems somewhat unlikely that it might be possible to possess one in the complete absence of the other. However, it is feasible that the Act was drafted in this way for purely practical reasons. It may have been envisaged that some doctors working in certain areas, or within a particular institutional or clinical setting, might frequently be involved in the initial identification and diagnosis of mental disorder but not the treatment, which would generally be undertaken elsewhere. It is more difficult to understand how doctors might be experienced in the treatment of the illness without knowing about the diagnosis.

Although the Act apparently requires a common level of special experience among doctors who are to be approved, it takes no account of the different areas of practice and expertise in those likely to use the legislation. The training and educational needs of those working in specialised areas (such as general adult psychiatry, care of detained patients, forensic practice and old age psychiatry) may be different from those of general practitioners, prison medical officers and police surgeons. They may also differ from the needs of psychiatrists working, for example, with children, who may need to be approved even though they are only infrequently involved in the use of the Act. It is therefore a moot point whether, in this context, the requirements for approval should be so broad and not more clearly defined.

Doctors approved under the Act have also been granted powers that implicitly give them an ethical responsibility, in that they can remove an individual's liberty and human rights. In certain circumstances, this is where those rights are least well protected. It might therefore be argued that there is a moral obligation to go appropriately equipped to perform the role of the approved doctor. It has been suggested that the legislation is worded specifically to allow discretion on the part of those using it and to retain a degree of flexibility in keeping with the variety of different clinical and practical circumstances in which it might be used. Practitioners given these special responsibilities should have a basic knowledge and understanding of the law in order that they can use their discretion as appropriate. At the same time, this commonality needs to be supplemented by a diversity of approach and background as represented by secondary and primary care doctors.

In practice, the power of approval is delegated to National Health Service Executive regional offices which 'must carry out such consultations and obtain such advice as the Secretary of State shall direct' (NHS Executive, 1996). Guidance on the approval procedures was first issued in Department of Health Circular HC(90)21 (Department of Health, 1990), subsequently superseded by HSG(96)3 (NHS Executive, 1996).

\section{The origins of specific training}

The guidance circular suggested that those seeking first-time approval should have gained the necessary experience. This can be achieved through involvement in appropriate post-registration clinical work full-time over 6 months, or through Membership of the Royal College of Psychiatrists or equivalent, or by being deemed to 'have acquired the necessary experience'. Reassuringly, the guidance also states that medical practitioners will need up-to-date knowledge, skills and attitudes. In addition, 'doctors seeking approval or reapproval may need to be encouraged to take part in relevant postgraduate training'. Thus, no less than 7 years after the Mental Health Act 1983 itself became law, the suggestion was made that 'expert' medical practitioners might require some specific training. This may have resulted from adverse comments received from voluntary organisations such as the National Schizophrenia Fellowship or from Members of the Mental Health Act Commission (such comments were passed on to N.B. when he was chairman of the former West Midlands Regional Health Authority).

Subsequently, HSG(96)3 set out a requirement that those seeking approval should attend a training course and that, in order to maintain approval, they should attend refresher training. Regional offices were tasked to provide such training either directly or by commissioning through educational bodies such as universities. The courses were to be accredited by the Royal College of Psychiatrists and the Royal College of General Practitioners but there was no specification for content or style.

Since then, there have been a number of key quality improvement initiatives in health and social service working that have underlined the principle of ensuring that staff employed are 'fit for purpose'. In this context, doctors approved as having special experience under the Act and authorised to make decisions for other adults in respect of liberty and the receipt of medical treatment must be clearly seen to warrant such approval. The development of the concepts of clinical governance and individual appraisal reinforce the need to ensure that the right thing is being done by the right person, in the right way, at the right time, every time (Department of Health, 1998, 1999). 
Unfortunately, in the area of mental health legislation, the right thing is not always done in the right way at the right time. This is reflected in the small but growing number of cases of 'faulty' detention, references in adverse incident inquiries to incorrect application of the Act and surveys of doctors' knowledge of mental health legislation (Blom-Cooper et al, 1995; Bhatti et al, 1998; Peay et al, 2001).

There therefore appears to be no question of the need for training for those seeking and maintaining approval under Section 12(2).

\section{Initial training for those seeking first-time approval}

A course for individuals seeking approval for the first time should be developed by a partnership involving, for example, the Regional or Deputy Regional Adviser in Psychiatry, the Postgraduate Medical Dean, the Royal College of General Practitioners, social services and educationalists. The course should include all appropriate subject areas, with a curriculum set in line with need and based on clearly stated aims and objectives (Harden, 1986).

In the West Midlands and elsewhere in the UK, such courses, developed in the light of experience, have now been in existence for some 6 years.

\section{Course content}

Course aims and objectives are suggested in Box 1 , and course content is outlined in Box 2 .

The course should use a variety of learning methods (e.g. lectures, small groups and debate) and teaching materials (e.g. video, case vignettes and legal rulings). Before attending the course, delegates should receive a resource pack that includes copies of the current Mental Health Act and the Code of

Box 1 Aim and objectives of initial training programmes

Aim

To ensure that applicants for Section 12(2) approval are familiar with the Mental Health Act and how it applies in clinical practice

Objectives

To understand the content of the Mental Health Act, its provisions and context

To consider clinical scenarios and how legislation may be used

To complete 'Section Forms' on simulated cases

To consider the quality of individual and team work required to implement legislation successfully
Practice together with a bibliography of key reading, for example landmark rulings and allied legislation (Human Rights Act 2000, Data Protection Act 1998, Court of Protection, Sex Offenders Act) and The Mental Health Act Manual (Jones, 2000).

For an average region, the course will need to be held twice a year, catering for 40-50 learners at a time. Thus, 80-100 new applicants will be capable of inception to Section 12(2) approval per year. The course may be run entirely on an in-house basis or, alternatively, may be commissioned using a specification drawn from Box 2. Our experience suggests that learners benefit from being grouped with experienced local medical and social work practitioners and service users.

This core content must be covered by all who are seeking approval. There is a case for supplementing, but not separating out, the needs of such groups as child and adolescent psychiatrists, who will have additional requirements, for example, to place this legislation alongside The Children Act.

The course must be evaluated by participants and should be under constant review, both in light of the evaluation and emerging case law and experience. The future curriculum will obviously be dictated by the results of the current reform of the Mental Health Act. It is likely that modules will need to be developed to cover in greater detail items such as:

- risk assessment and management

- care planning and its interface with the Mental Health Act Tribunal

- assessment and care planning for patients with personality disorder.

\section{General practitioners}

It is clearly necessary to recruit primary care physicians. Individual patients obviously benefit from an experienced primary care perspective during the assessment process. Local mental health services may also benefit from having informed and enthusiastic general practitioners as potential aids and allies. The HSG(96)3 guidelines suggest that steps be taken to enhance recruitment and this must be reinforced by producing courses that are relevant to primary care and easily accessible. The 'primary care' group may also include general practitioners working in prisons or prison medical officers.

\section{'Special' learners}

Two groups of individuals with particular needs come immediately to mind. The first is doctors coming from overseas to employment at senior levels. They have qualifications equivalent to Membership of the Royal College of Psychiatrists but do not have 


\section{Box 2 The content of an initial training programme and suggested method of delivery}

Why there is a Mental Health Act

The Act in practice, when and how to use it

The role of key players, e.g. approved social workers

The experience of service users and carers

Use of the Act in specific settings, e.g. acute hospitals

The use of the Act in community settings

The Mental Health Review Tribunal

Human Rights Act 2000, Data Protection Act 1998

Consent to treatment, capacity to consent

Problem cases: what can and has gone wrong?
Lecture and discussion

Lecture and small-group work on case scenarios

Lecture and video

Lecture and small-group work on case scenarios

Lecture and small-group work on case scenarios

Lecture and small-group work on case scenarios

Lecture and discussion

Lecture and discussion

Lecture and small-group work on case scenarios

Lecture and discussion particular knowledge or experience of the UK Mental Health Act. In order to expedite employment, the local medical director may induct and accredit an individual using a training programme agreed by the Regional Approval Panel, such that provisional approval may be granted under the Act. The second group consists of non-consultant career grade doctors who may never have fulfilled the criteria for approval either as a psychiatrist-in-training or as a general practitioner. Here, it is suggested that individuals undergo a similar introductory training course and attend the initial training course before approval is granted.

\section{Refresher training for those already approved}

Training should be available to help ensure that doctors keep their knowledge of mental health legislation and their attitudes to its use in practice up to date. Successful refresher training courses should be multi-professional at all levels, from the original planning and management of the course through to the speakers and delegates. Ideally, they should be arranged on a locality basis. Experience in the West Midlands over the past 5 years supports the notion that each locality can arrange and support a successful annual event. The regional office is notified of these courses, for monitoring purposes and to enable those from other localities to gain access to them and to share experiences.

Box 3 lists some of the uses and benefits of refresher courses. For individual doctors, refresher training should be part of continuing professional development. For the purposes of reapproval, a minimum of 9 hours of such training in a 5-year period is suggested, spread over at least three separate sessions (NHS Executive, 2001). This is a notional figure that reflects the spirit of HSG(96)3 and the reality of the current requirements of different regional panels. It should be emphasised that the training for initial approval and subsequent refresher training are part of a life-long learning process and not one-off experiences intended or designed to be definitive. Sufficient time should be devoted to discussion of practitioners' attitudes to the use of the Mental Health Act and the approval training courses. There is a danger that this type of 'required' training might be viewed as a chore to be endured for the sake of obtaining the appropriate certificate of attendance.

\section{Assessment of learning outcome}

Attention must be given to the outcome of training courses if the process is not to resemble the Task of Sisyphus: endless effort resulting in little benefit. Ultimately, any assessment will be about the quality of clinical work undertaken by approved practitioners. It would be hoped, for example, that there would be fewer headlines such as 'Hospital errors freed man who killed two' over a story which states that 'he ... gained leave ... from a junior locum ... who did not realise he had been detained under the Mental Health Act' (Anonymous, 2001).

\section{Box 3 The potential of refresher courses}

Such courses might offer:

- a forum for local issues

- feedback after visits by the Mental Health Act Commission

- presentation of local audit or research findings

- discussion of the enactment of guidance (e.g. Section 136) and problems with interpretation of legislation

- an opportunity to tie in new legislative development and/or related quality initiatives (e.g. An Organisation with a Memory, Department of Health, 2000)

- the possibility of consolidating existing links and forging new local relationships around a shared agenda and interests (e.g. with prisons, the probation service and the police) 
Although some form of assessment may be made of those attending initial training courses, any formal assessment process is likely to prove impractical. The development of standardised questions of sufficient rigour and variety to be used on a regular, perhaps twice-yearly, basis is difficult enough. To then consider the practical implications of failure in the assessment for an individual or an organisation suggests that, although it might be desirable, formal assessment will prove unworkable.

However, the consolidation of appraisal for all medical staff offers other opportunities. For the first time, individual medical staff, including those in senior positions, are to have the opportunity to discuss their work, their learning and their plans with another medical practitioner on a formal basis (Department of Health, 2001; Khalil et al, 2001). Learning about, and the execution of, the doctor's duties under the Mental Health Act should become a constituent part of that appraisal. Thus, learning outcomes such as knowledge of the Code of Practice or local Section 136 policy can be discussed. Working practices can be examined in a number of ways, including summarising the results of the scrutiny of forms and examining a sample of individual cases in order to share an understanding of decisionmaking processes. A related possibility is the use of '360-degree appraisal' (team observation), which could include the views of approved social workers and doctors such as general practitioners, police surgeons and forensic medical examiners.

\section{Conclusions}

Over the past decade, systems have grown in response to the need to develop training for doctors who are to be approved under Section 12(2) of the Mental Health Act 1983. This allows standards to be applied with regard to 'special experience' when approval is granted and subsequently renewed. The form and content of courses, as outlined above, is a significant move in the direction expected in a modern public service. However, this must be seen as the beginning and not the end of the story. Studies of the knowledge level of approved doctors give no grounds for complacency (Bhatti et al, 1998). Evidence gathered in preparation for the issue of updated statutory instruments also suggests that the application of approval criteria varies across England. This shows itself in decisions over the approval of locum doctors and the provision and content of training courses.

It would seem that there is now a clear case for the development of a national syllabus and accepted standards of training, as well as agreement on the application of approval criteria. Targets could also be set in terms of the numbers of approved doctors required. It would be useful to complete this task in advance of the reform of the Mental Health Act, to ensure that the medical profession is prepared for the changes.

\section{References}

Anonymous (2001) The Guardian, 28 November, p. 9.

Bhatti, V., Kenney-Herbert, J., Cope, R., et al (1998) Knowledge of current mental health legislation among medical practitioners approved under section 12(2) of the Mental Health Act 1983 in the West Midlands. Health Trends, 30, 106-108.

Blom-Cooper, L., Hally, H. \& Murphy, E. (1995) The Falling Shadow: One Patient's Mental Health Care, 1978 to 1993. The Report of the Committee of Inquiry into the Events Leading up to and Surrounding the Fatal Incident at the Edith Morgan Centre, Torbay, on 1 September 1993. London: Duckworth

Department of Health (1990) Circular HC(90)21. London: Department of Health.

- (1998) A First Class Service: Quality in the New NHS. London: Department of Health.

- (1999) Clinical Governance: Quality in the New NHS. London: Department of Health.

- (2000) An Organisation with a Memory. Report of an Expert Group on Learning from Adverse Events in the NHS. London: Stationery Office.

- (2001) Consultant Contract: Annual Appraisal for Consultants, Advance Letter (MD) 5/01. London: Department of Health.

Harden, R. M. (1986) Ten questions to ask when planning a course or curriculum. Medical Education, 20, 356-365.

Jones, R. (2000) The Mental Health Act Manual (7th edn). London: Sweet and Maxwell.

Khalil, S., Parry, E., Brown, N., et al (2001) Individual appraisal for senior medical staff. Psychiatric Bulletin, 25, 166-169.

NHS Executive (1996) Guidance HSG(96)3. In: Approval of Doctors under Section 12 of the Mental Health 1983. London: Department of Health.

- (2001) West Midlands Regional Advisory Panel on the Approval of Medical Practitioners under Section 12 of the Mental Health Act 1983, Policy Guidance for Panel Members. London: Department of Health.

Peay, J., Roberts, C. \& Eastman, N. (2001) Legal knowledge of mental health professionals: report of a national survey. Journal of Mental Health Law, 5, 44-55.

R. v. Trent Regional Health Authority, ex parte Somaratne (1993) 18 BMLR 133; The Times, 10 December.

\section{Multiple choice questions}

1 Section 12 refresher training:

a should be part of an individual's personal development plan

$b$ is suggested for the purpose of reapproval in health service guidance

c should be multi-professional and multi-agency

d may include consideration of local policy and practice

e may include consideration of contemporary legal issues.

2 Approval under Section 12(2) of the Mental Health Act 1983:

a relates to medical recommendations for compulsory admission to hospital

$b$ is granted by the Secretary of State

c requires 'special experience in the diagnosis and treatment of mental disorders' 
$\mathrm{d}$ requires only 'special experience' as defined in the Act

$\mathrm{e}$ is not a nationally uniform process.

3 Section 12 approval courses:

a have specified requirements

b have recognised national standards

c were initially the responsibility of regional offices

d may include material unrelated to the use of mental health legislation

e are required to include a formal examination process.

MCQ answers

$\begin{array}{lllll}\text { 1 } & & 2 & 3 \\ \text { a } & \text { T } & \text { a } & \text { F } & \text { a } \\ \text { b T } & \text { b T } & \text { b F } \\ \text { c T } & \text { c T } & \text { c T } \\ \text { d T } & \text { d T } & \text { d T } \\ \text { e T } & \text { T } & \text { T } & \text { e } & \text { F }\end{array}$

\section{INVITED COMMENTARY ON Training for approval under Section 12(2). Ethics and implications of assessments}

Now that training under Section 12 (Section 20 in Scotland) of the Mental Health Act 1983 is mandatory under the NHS Executive Guidelines HSG(96)3 (1996) both prior to and while maintaining approval, discussion of the educational objectives and how to achieve them is overdue. The article by Brown \& Humphreys (2003, this issue) is a welcome introduction to the debate. Given that psychiatrists may move between different legal jurisdictions and that there is a constant stream of new and relevant case law (not to mention that we may soon have a new Mental Health Act), it is clearly important that training is about principles, issues and asking questions rather than a didactic teaching of facts. One must consider what are the relevant issues.

\section{Section 12, Mental Health Act 1983}

Section 12 relates only to the authority needed to make one of the medical recommendations to detain patients under the Mental Health Act 1983. If that doctor does not have previous knowledge of the patient, the other medical recommendation should, if practicable, be made by a doctor who does have. This is often interpreted, very reasonably, as meaning a psychiatrist (the specialist) and the patient's general practitioner (previous knowledge of the patient, the family and so on). The Mental Health Act Code of Practice suggests that if neither doctor has previous knowledge of the patient, then both should be approved under Section 12 .

Psychiatrists do not need to be approved under Section 12 in order to be the responsible medical officer (RMO) for detained patients or to give evidence to Mental Health Review Tribunals. Since 1996, doctors providing after-care under Section 117 are required to be approved under Section 12, as are doctors acting as RMO for patients subject to Section 25 (Mental Health (Patients in the Community) Act 1995). It could be argued that Section 12 training should deal with issues only in relation to undertaking medical assessments under the Act and providing after-care.

Why, for so many years, was training not thought to be necessary? History, as ever, is instructive. The requirement for two medical recommendations prior to admission to a mental hospital was introduced in the 1890 Lunacy Act. Throughout the 19th century, there had been a vast increase in the number of detained patients who were paupers and this was thought by many people to be unjustified, in part because admission was arranged by relatives to remove their embarrassing kith and kin.

In 1845, James Luke Hansard had formed the Alleged Lunatic Friends' Society 'for the protection of the British subject from unjust confinement on the grounds of mental derangement'. The 1890 Act prevented all admissions to mental hospitals (apart from the Bethlem Royal) unless two doctors certified that the person was a lunatic and therefore could be detained, if others thought it appropriate.

This point is crucial. The role of the certifying doctors was not to say that the person should be detained in hospital but they could be if others thought it necessary. It is for this reason that doctors do not apply to have patients detained in hospital. The application is made by an approved social 